\title{
The Measurement of Corporate Brand: Based on a Stakeholder Perspective
}

\author{
YANG Yi-weng ${ }^{1, a^{*}}$, ZHANG Xin-rui ${ }^{1, b}$, TONG Ze-lin ${ }^{1, c}$, and JI Xue-hong ${ }^{1, d}$ \\ ${ }^{1}$ School of Economics and Management, North China University of Technology, Beijing 100144, \\ China

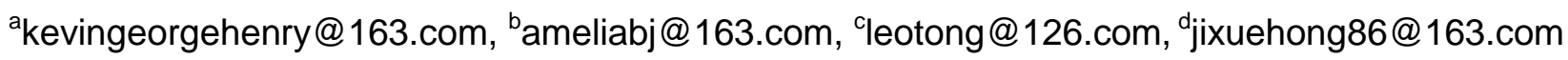

Keywords: corporate brand; dimension; measurement; stakeholder perspective

\begin{abstract}
Despite considerable interest in the topic of corporate brand, attempts at its measurement have been scarce. Most of the existing researches are focus on the impact of corporate brand on consumer decision. But corporate brand is not only for consumers, but for other stakeholders too. The paper firstly proposes a nine-dimensional structure of corporate brand from a stakeholder perspective. Then, the research develops and validates a set of corporate brand scales (CBS) through questionnaire design, data collection, scales purification, reliability analysis, and validity analysis. Compared with previous scales, CBS is more comprehensive and stable, suggesting it paves the way for further empirical researches on the overall corporate level.
\end{abstract}

\section{Introduction}

Chinese brands are large but not strong, and China lacks true global brands. How to build Chinese global brands? The high homogeneity of products, the acceleration of technology upgrades, and the short-termism of product life cycle make it unsustainable to support corporations just by some key product brands, and building up strong corporate brand is the path we cannot surpass. Despite the increased attention received by corporate brand, empirical evidence has been scarce. Further, the rare attempts at the dimensions and measurement of corporate brand exhibit some limitations. Hence, this paper aims to fill these gaps. We expect to contribute to our understanding of these areas by providing empirical evidence of the multidimensionality structure of corporate brand. We also expect the results have implications for brand management in practice.

\section{Corporate Brand Dimensions and Gaps in the Literature}

There is no satisfactory consensus regarding the dimensions of corporate brand in previous researches. Hatch and Schultz (2001) proposed that corporate brand consists of three elements: vision (facing managers), culture (facing employees), and image (facing external stakeholders) ${ }^{[1]}$. Based on this, Knox and Bickerton (2003) stated that corporate brand management contains four elements: vision, image, culture, and competitive landscape management ${ }^{[2]}$. We suggest that the above two researches mainly discuss the factors we should consider in corporate brand management practices to build strong corporate brands. Balmer and Greyser (2006) presented that corporate brand includes six elements: Culture, Communication, Conceptualisations, Constituencies, and Covenant $^{[3]}$. Aaker (2004) stated that corporate brand contains seven elements: heritage, assets and capabilities, people, values and priorities, local vs. global orientation, citizenship, and corporate performance and size ${ }^{[4]}$. We suggest that the main limitation of the above two researches is they don't point out the logical relationship between different dimensions. 
Based on the analysis above, we argue that corporate brand consists of three levels: external level, culture level, and strategy level. The external level mainly faces external stakeholders, including four dimensions: product and service, corporate capacity, corporate social responsibility, and corporate reputation. The culture level mainly faces employees, including three dimensions: corporate history, country-of-origin, and core value. The strategy level mainly faces managers, including two dimensions: corporate vision and corporate goal. The dimensions of the strategy level are the guiding power of the dimensions of the culture level; the dimensions of the culture level are the internal driving force of the dimensions of the external level. On the basis of the nine-dimensional structure of corporate brand from a stakeholder perspective, we will develop and validate a set of corporate brand scales (CBS) in the next section.

\section{Development and Validation of CBS}

Questionnaire Design. (1) Published literatures are extensively consulted for the purpose of generating items. (2) We replenish new items through group discussions and in-depth interviews. (3) We then invite professors, $\mathrm{PhD}$ students and masters to discuss, check, and evaluate those items. Through the above work, we get the first draft of CBS, including 58 items.

Data Collection. This research chooses China Mobile as survey brand. A combination of web survey and field survey is employed to collect data. All items except demographic information are measured on a 7-point Likert-type scale form "strongly disagree" (1) to "strongly agree" (7). The questionnaire survey begins on May, 2014; ends on August, 2014. We distribute 600 questionnaires, take back 320 valid questionnaires; the valid response rate is $53.3 \%$.

Scales Purification. (1) If the item-total correlation coefficient is below .40; or if the Cronbach's $\alpha$ value increases after we delete the present item, then we drop this kind of item. (2) We also drop items whose factor loadings are below .40 after rotation; as well as items which land on more than two dimensions or don't land on any one of the dimensions. Overall, 31 items are dropped from the original pool of 58 items. Through scales purification, we get the final draft of CBS, including 27 items (see Appendix A).

Reliability Analysis. (1) Exploratory factor analysis is used for reliability analysis. The results show that the KMO value of all 27 items is .90; the significance level of Bartlett's Test of Sphericity is below .05, which indicates the data is fit for factor analysis. We distinguish different dimensions through varimax rotation method. The results of scree plot show that the variation of the first eight factors is much larger; and the variation gets much smaller from the ninth factor, which indicates that we should extract eight main composition factors. Viewed from the contribution rate of variance, the first eight factors can explain $73.00 \%$ information (beyond the $60 \%$ standard), which indicates that extracting eight factor is appropriate. The varimax orthogonal rotation method is employed, the results show that 27 items are assigned to eight component factors very well, and the factor loading of every item is above .40, which indicates good effect. (2) Factor Connotation Analysis. The first factor includes three items: overall quality, quality stability, and word of mouth of product, so it can be defined as "product and service". The second factor consists of two items: innovation capacity and R\&D capacity, so we can call it "corporate capacity". The third factor includes three items: social contribution, community assistance, and public welfare project, so it can be defined as "corporate social responsibility". The fourth factor contains three items: corporate awareness, global reputation, and industry leader, so we can define it as "corporate reputation". The fifth factor includes three items: manager awareness, glorious history, and history exhibition, so it 
can be defined as "corporate history". The sixth factor includes six items: affluence degree, openness degree, education level, overall product quality, technical content, and technological level, so we can call it "country-of-origin". The seventh factor consists of three items: management style, management system, and operation philosophy, so it can be defined as "core value". The eighth factor contains four items: vision guide, vision coordination, goal consensus, and goal coordination, so we can define it as "vision and goal". The eight-dimensional structure of CBS gotten through factor analysis is similar to the nine-dimensional structure of corporate brand we proposed in the literature review section. Because corporate vision and corporate goal are too similar to be distinguished by stakeholders, SPSS software combines these two dimensions into a new one. The new dimension includes two items of corporate vision and two items of corporate goal, so it can be defined as "vision and goal". (3) Internal Consistency Analysis. We use Cronbach's $\alpha$ calculated by the reliability analysis of SPSS software to test each dimension's and the overall scales' internal consistency. According to Devellis's suggestion ${ }^{[5]}$, the Cronbach's $\alpha$ of corporate reputation is .69 (modest); the Cronbach's $\alpha$ of corporate history is .70 (good); the Cronbach's $\alpha$ of other dimensions are all in the range of .80 .90 (very good). Moreover, the Cronbach's $\alpha$ of the overall scales is .93 (very good); meanwhile, if we drop any one of the items, the Cronbach's $\alpha$ will decrease. All the above indicates excellent internal consistency of CBS.

Validity Analysis. (1) Content Validity. We try to improve the content validity of CBS by extensive literature readings, group discussions and in-depth interviews. We then invite experts to check, amend, and replenish items. Based on the above, we ensure the content validity of CBS. (2) Predictive Validity and Construct Validity. Based on the Theory of Reasoned Action ${ }^{[6]}$, we propose that stakeholders' perception of a corporate brand can positively predict their attitude toward this corporate. So we assess the predictive validity and construct validity of CBS by examing the relationship between corporate brand and stakeholder attitude. We conduct regression analysis with stakeholder attitude as the dependent variable and corporate brand as the explanatory variable. The results show that our corporate brand measure is indeed a significant predictor of stakeholder attitude, at $\mathrm{p}<.05$, which demonstrates good predictive validity and construct validity. (3) Convergent Validity and Discriminant Validity. We use the Pearson correlation analysis to test the relationship between each two dimensions. The results show that each two of the eight dimensions are significantly positive correlated; and the correlation coefficients are all between .19 and .54, which indicates moderate correlations among these eight dimensions. All the above demonstrates good convergent validity and discriminant validity of CBS.

\section{Discussion}

The Advantages of CBS. (1) Comprehensiveness. Most of the existing researches are focus on the effects of corporate brand on consumer decision. But corporate brand is not only for consumers, but also for other stakeholders. Consequently, the scales used by previous researches cannot reflect the connotation of corporate brand comprehensively. Based on the eight-dimensional structure of the corporate brand proposed in the literature section, we develop and validate a set of CBS from a stakeholder perspective. So CBS is more comprehensive than previous scales. (2) Stability. Most of previous scales haven't been validated by empirical analysis. We use a standard scales development program to develop and validate a set of CBS systematically; the reliability and validity analysis demonstrate that CBS has good reliability and validity. So CBS is more stable than precious scales. 
Managerial Implications. CBS enables managers to better measure, track and manage corporate brand. (1) Managers can use CBS to measure both the overall corporate image and every single dimension, so as to master the current situation of corporate brand. (2) In order to improve the pertinence of brand management, managers must make clear how different stakeholders perceive corporate brand. It is hard o answer this key question due to the lack of good measuring tools previously, while CBS can reflect the perception of different stakeholders more comprehensively and clearly. So managers can use CBS to implement strategic brand management more specifically. (3) Every kind of stakeholder is inclined to develop long-term relationship with corporations which have excellent corporate image. On the basis of CBS, stakeholders can measure and compare different corporate images directly, so as to improve the efficiency and quality of brand decisions. (4) Managers can use CBS to measure and track the development status, evolvement rule, and future trends of corporate brand, so as to adjust brand management strategies and tactics accordingly. CBS can also help managers to identify the advantages and gaps of different dimensions of corporate brand between the present corporate and competitors, so as to clarify key resource investment fields and improve core competence of the present corporate brand.

\section{Limitations and Directions for Future Research}

First, this paper doesn't use confirmatory factor analysis to further validate the stability of the eight-dimensional structure of corporate brand. Future researches can collect new data to do confirmatory factor analysis to verify the structure stability of CBS. Second, this research adopts convenient sampling method to collect data, so the representation of sample has some limitations. Future researches can use stratified sampling method involved different kinds of stakeholders to collect data. Third, on the overall corporate level, future researches can build mechanism model of corporate brand on stakeholders. The present paper paves the way for future empirical researches.

\section{Appendix A. Corporate Brand Scales (CBS)}

\begin{tabular}{|c|c|c|}
\hline Dimensions & Items & Cronbach's $\alpha$ \\
\hline \multirow{3}{*}{$\begin{array}{c}\text { Product and } \\
\text { Service }\end{array}$} & $\mathrm{Q}_{1}$ The overall quality of products and services of this corporate is high. & \multirow{3}{*}{0.863} \\
\hline & $\mathrm{Q}_{2}$ The stability of products and services of this corporate is good. & \\
\hline & $\mathrm{Q}_{3}$ The word of mouth of products and services of this corporate is good. & \\
\hline \multirow{2}{*}{$\begin{array}{c}\text { Corporate } \\
\text { Capacity }\end{array}$} & $\mathrm{Q}_{4}$ The innovation capacity of this corporate is strong. & \multirow{2}{*}{0.829} \\
\hline & $\mathrm{Q}_{5} \quad$ The $\mathrm{R} \& \mathrm{D}$ capacity of this corporate is strong. & \\
\hline \multirow{3}{*}{$\begin{array}{c}\text { Corporate Social } \\
\text { Responsibility }\end{array}$} & Q6 The products and services of this corporate contribute to society. & \multirow{3}{*}{0.843} \\
\hline & $\mathrm{Q}_{7}$ This corporate gives assistance to the local communities. & \\
\hline & $\mathrm{Q}_{8} \quad$ This corporate supports public welfare projects. & \\
\hline \multirow{3}{*}{$\begin{array}{l}\text { Corporate } \\
\text { Reputation }\end{array}$} & $\mathrm{Q}_{9}$ The awareness of this corporate is high. & \multirow{3}{*}{0.688} \\
\hline & $\mathrm{Q}_{10}$ This corporate enjoys high global reputation. & \\
\hline & $\mathrm{Q}_{11}$ This corporate is an industry leader. & \\
\hline \multirow{3}{*}{ Corporate History } & $\mathrm{Q}_{12}$ The awareness of managers of this corporate is high. & \multirow{3}{*}{0.704} \\
\hline & $\mathrm{Q}_{13}$ This corporate has a glorious history. & \\
\hline & $\mathrm{Q}_{14}$ This corporate often exhibits its history by all kinds of ways. & \\
\hline \multirow{2}{*}{ Country-of-Origin } & $\mathrm{Q}_{15}$ The affluence degree of China is high. & \multirow{2}{*}{0.889} \\
\hline & $\mathrm{Q}_{16}$ The openness degree of China is high. & \\
\hline
\end{tabular}




\begin{tabular}{|c|c|c|}
\hline & $\mathrm{Q}_{17}$ The education level of China is high. & \\
\hline & $\mathrm{Q}_{18}$ The overall product quality of China is good. & \\
\hline & $\mathrm{Q}_{19}$ The overall product technical content of China is high. & \\
\hline & $\mathrm{Q}_{20}$ The overall product technological level of China is high. & \\
\hline \multirow{3}{*}{ Core Value } & $\mathrm{Q}_{21}$ The management style of this corporate is different from the rest. & \multirow{3}{*}{0.844} \\
\hline & $\mathrm{Q}_{22}$ This corporate has a set of clear management system. & \\
\hline & $\mathrm{Q}_{23}$ This corporate has a set of clear operation philosophy. & \\
\hline \multirow{4}{*}{ Vision and Goal } & $\mathrm{Q}_{24}$ Vision guides this corporate to move in the right directions. & \multirow{4}{*}{0.812} \\
\hline & $\begin{array}{l}\mathrm{Q}_{25} \text { Vision helps this corporate to coordinate internal and external } \\
\text { resources. }\end{array}$ & \\
\hline & $\mathrm{Q}_{26}$ Members of this corporate share broad consensus on corporate goals. & \\
\hline & $\mathrm{Q}_{27}$ This corporate coordinates long-term ideas and short-term goals well. & \\
\hline
\end{tabular}

\section{Acknowledgment}

The author would like to acknowledge the support of the Humanities and Social Sciences Foundation of Ministry of Education of China (No. 14YJC630167), the Scientific Research Starting Foundation of North China University of Technology (No. 14HENRY0020), the Comprehensive Reform Program of Beijing Municipal Colleges and Universities to Promote the Cultivation of Talents-Graduate Innovation Platform Construction (No. 14085-50), and the Outstanding Young Teachers Training Program of North China University of Technology (No. 14085).

\section{References}

[1] M.J. Hatch, M. Schult, Are the strategic stars aligned for your corporate brand?, Harvard Business Review 79 (2001) 128-134.

[2] S. Knox, D. Bickerton, The six conventions of corporate branding, European Journal of Marketing 37 (2003) 998-1016.

[3] J.M.T. Balmer, S.A. Greyser, Corporate marketing: integrating corporate identity, corporate branding, corporate communications, corporate image and corporate reputation, European Journal of Marketing 40 (2006) 730-741.

[4] D.A. Aaker, Leveraging the corporate brand, California Management Review 46 (2004) 6-18.

[5] R.F. Devellis, Scale development: theory and application, Sage Publications, California, 2003.

[6] M. Fishbein, I. Ajzen, Belief, attitude, intention, and behavior: an introduction to theory and research, Addison-Wesley, Boston, 1975. 